\section{Will SafetyNet adequately protect confidentiality?}

The sensitive data collected by SafetyNet must be absolutely protected against non-authorised access. Accell uses Unix file permissions and offers very powerful security, allowing developers to restrict access to files, records or even individual items of data. Only professional mental health staff will have access to the system and this will be tightly controlled through passwords which will be changed regularly. Another key security measure is incorporated in the computer operating system which maintains a detailed daily log of who used the system and when.

SafetyNet is also being written under the database programme DBase IV (Ashton Tate) on computers using the MSDos operating system. This package offers very similar features to those already described and can be used as a stand alone package or on a small local area network around a 80386 IBM compatible computer (up to five users). This version will be made freely available to interested health workers. Users wishing to upgrade to the unix version will be able to transfer their data as the systems use comparable codings and datasets. Anyone interested in a demonstration of the system should contact
Dr Jason Taylor at 309 Gray's Inn Road, London WCIX 8QF.

\section{Acknowledgements}

We wish to thank Drs Patrick Campbell and Chris Pantelis for their contributions towards developing the dataset and to Professor Julian Leff for his assistance in approaches to evaluating the system. We also wish to thank the Friern Trustees, Marks and Spencer plc, the Paul Getty Trust, the Phyllis Gardiner Trust and others who have contributed towards the completion of the Camden surveys of schizophrenia and the development of SafetyNet.

\section{References}

KraWiecka, M., Goldberg, D. \& Vaughn, M. (1977) A standardised psychiatric assessment scale for rating chronic psychotic patients. Acta Psychiatrica Scandinavica, 55, 299-308.

Pantelis, C., Taylor, J. \& Camprell, P. (1988) The South Camden Schizophrenia Survey - An experience of community based research. Bulletin of the Royal College of Psychiatrists, 12, 98-101.

WYKES, T. \& STURT, E. (1986) The measurement of social behaviour in psychiatric patients: An assessment of the reliability and validity of the Social Behaviour Schedule. British Journal of Psychiatry, 148, 1-12.

\title{
Health Care Buzz Phrase Generator
}

Think of a random three-digit number - or you could generate it on your computer - and take the corresponding words from each of the three columns. When put together the three words form an expression which will not have any particular meaning, but it will provide the user with an authoritative, progressive and incisive ring to his debate.

\footnotetext{
0 Coordinated

1 Integrated

2 Systematised

3 Specialised

4 Concerted

5 Synchronised

6 Compatible

7 Functional

8 Comprehensive

9 Optional
}

$\begin{array}{ll}0 & \text { Management } \\ 1 & \text { Organisational } \\ 2 & \text { Logistical } \\ 3 & \text { Monitored } \\ 4 & \text { Incremental } \\ 5 & \text { Policy } \\ 6 & \text { Resource } \\ 7 & \text { Control } \\ 8 & \text { Review } \\ 9 & \text { Proportional }\end{array}$
0 Potential
1 Options
2 Flexibility
3 Facility
4 Capability
5 Programming
6 Philosophy
7 Concept
8 Strategy
9 Format

Thus 100 gives "integrated management potential" or 766 gives "functional resource philosophy".

Even cursory reference to any health planning or policy document will show just how much time would have been saved by the authors had they used the instrument.

R. G.S. Platts Royal National Orthopaedic Hospital, Stanmore 